\title{
The Solution of Fourth Order Boundary Value Problem Arising out of the Beam-Column Theory Using Adomian Decomposition Method
}

\author{
Omer Kelesoglu \\ Department of Civil Engineering, Technology Faculty, Firat University, 23119 Elazig, Turkey \\ Correspondence should be addressed to Omer Kelesoglu; okelesoglu@firat.edu.tr
}

Received 23 November 2013; Accepted 2 March 2014; Published 30 March 2014

Academic Editor: Sergii V. Kavun

Copyright (C) 2014 Omer Kelesoglu. This is an open access article distributed under the Creative Commons Attribution License, which permits unrestricted use, distribution, and reproduction in any medium, provided the original work is properly cited.

Adomian decomposition method (ADM) is applied to linear nonhomogeneous boundary value problem arising from the beamcolumn theory. The obtained results are expressed in tables and graphs. We obtain rapidly converging results to exact solution by using the ADM. This situation indicates that the method is appropriate and reliable for such problems.

\section{Introduction}

It is possible to model many of the physical events that take place in nature using linear and nonlinear differential equations. This modeling enables us to understand and interpret the particular event in a much better manner. Thus, finding the analytical and approximate solutions of such models with initial and boundary conditions gain importance. Differential equations have had an important place in engineering since many years. Scientists and engineers generally examine systems that undergo changes.

Many methods have been developed to determine the analytical and approximate solutions of linear and nonlinear differential equations with initial and boundary value conditions and among these methods, the ADM [1-6], homotopy perturbation method [7-11], variational iteration method [12-19], and homotopy analysis method [20-25] can be listed. Package software such as Matematica, Maple, or Matlab is used to overcome tedious algebraic operations when using these methods. The determination of the analytical and approximate solutions of linear and nonlinear differential equations is an important topic for civil engineering, because these equations are the mathematical models of complex events that occur in engineering.

In this study, the approximate solution of the fourth order linear nonhomogeneous differential equation with initial and boundary conditions that arises in the beam-column theory will be determined via the ADM and comparisons will be made with the existing results in the literature.

The ADM was first put forth in the 1980s by an American scientist named Adomian [26]. This method is based on the decomposition of the unknown function. Using this method it is possible to determine the approximate solutions for the linear and nonlinear ordinary and partial differential equations. The ADM has been used effectively by researchers during 1990 and 2007 especially for the solution of differential and integral equations [27-32]. Using this method a nonlinear problem can be applied directly without discretization and linearization. Hence, this is a method that is preferred by researchers.

In this study, the analytical and approximate solutions of a fourth order linear boundary value problem were calculated using the ADM. In addition, the fourth order linear ordinary differential equation set used in the beam-column theory was solved under specific boundary conditions. The ADM used provides realistic solutions without changing the linear or nonlinear differential equation model. Numerical results close to the real solution can be found by calculating the terms of the limited number of decomposition series. It is possible to find the numerical solution of a differential equation using this method without the necessity of indexing. 


\section{Adomian Decomposition Method}

The method has many advantages in comparison with many other traditional methods such as Finite differences, Finite elements, and Galerkin method [33-35]. The method gives converging results adapted to the problems. It is a disadvantage that convergence interval is small and the calculation of the ADM polynomials occurs in nonlinear problems in the ADM.

We now consider second order nonlinear ordinary differential equations with initial conditions. This equation can be written in an operator by

$$
L u+R u+N u=f,
$$

where $L$ is the lower-order derivative, which is assumed to be invertible, $R$ is a linear differential operator of order greater than $L, N$ is a nonlinear differential operator, and $f$ is a source term. We next apply the inverse operator $L^{-1}$ to both sides of (1) and use the given initial conditions to get

$$
u(x)=u(0)+x u^{\prime}(0)+L^{-1}(g)-L^{-1}(R u)-L^{-1}(N u),
$$

where

$$
L=\frac{d^{2}}{d x^{2}}, \quad L^{-1}=\int_{0}^{x} \int_{0}^{x} d x d x
$$

The ADM consists in decomposing the unknown function $u(x)$ of any equation into a sum of infinite number of components given by the decomposition series

$$
u(x)=\sum_{n=0}^{\infty} u_{n}(x)
$$

where the components $u_{n}(x), n \geq 0$ are to be determined in a recursive manner. The nonlinear term $N u$ will be decomposed by the infinite series of polynomials given by

$$
N u=\sum_{n=0}^{\infty} A_{n}
$$

where $A_{n}$ are Adomian polynomials $[1,36]$. Substituting (3) and (4) into (2) gives

$$
\sum_{n=0}^{\infty} u_{n}=u_{0}(x)-L^{-1} R\left(\sum_{n=0}^{\infty} u_{n}(x)-L^{-1} \sum_{n=0}^{\infty} A_{n}\right),
$$

where

$$
u_{0}(x)=u(0)+x u^{\prime}(0)+L^{-1}(g)
$$

The various components $u_{n}$ of the solution $u$ can be easily determined by using the recursive relation

$$
\begin{aligned}
u_{0}(x) & =u(0)+x u^{\prime}(0)+L^{-1} g(x), \\
u_{k+1}(x) & =-L^{-1}\left(R u_{k}\right)-L^{-1}\left(A_{k}\right), \quad k \geq 0 .
\end{aligned}
$$

In order to obtain the numerical solutions of $u(x)$ closed solution function using the decomposition method;

$$
\varphi_{n}=\sum_{k=0}^{n} u_{k}(x) \quad k \geq 0,
$$

being; the term,

$$
u(x)=\lim _{n \rightarrow \infty} \varphi_{n}
$$

can be calculated by taking into account the reduction formula (8). In addition, the series solution of the decomposition written as (10) generally yields results that rapidly converge for physical problems. The convergence of the decomposition series has been examined by many researchers in the literature. The convergence of the decomposition series has been examined theoretically by Cherruault [37]. In addition to these studies, Abbaoui and Cherruault have suggested a new approach in determining the convergence of the decomposition series [38]. These authors have determined the convergence of the decomposition series method by giving new conditions.

\section{The Application of the ADM to the Linear Problem with Boundary Condition That Arises in Beam-Column Theory}

3.1. Problem Definition. Fourth order differential equations consist of various physical problems that are related to the elastic stability theory. Differential relations should be established between the effects of various cross-section effects in order to understand beam-column problems better.

When a cross section of distance $d x$ shown in Figure 1(b) is taken from a beam-column subject to both the $P$ axial load and the $q$ spread load perpendicular to the axis as shown in Figure 1(a), internal forces arise in the element. When the equilibrium equation in the $y$ direction is written with

$$
q=-\frac{d V}{d x}
$$

the following ordinary differential equation is found [39-42]:

$$
-V+q d x+(V+d V)=0 .
$$

The algebraic sums of the forces acting on both surfaces of the cross-section element are the same due to equilibrium. Consider

$$
M+q d x \frac{d x}{2}+(V+d V) d x-(M+d M)+P \frac{d y}{d x}=0 .
$$

Here, $V$ is the shear force acting on the surface of the element, whereas $M$ is the bending moment that tries to bend the cross-section element.

If rotations are assumed to be small and the second order terms in terms of $d x$ are neglected, then (13) becomes

$$
V=\frac{d M}{d x}-P \frac{d y}{d x}
$$




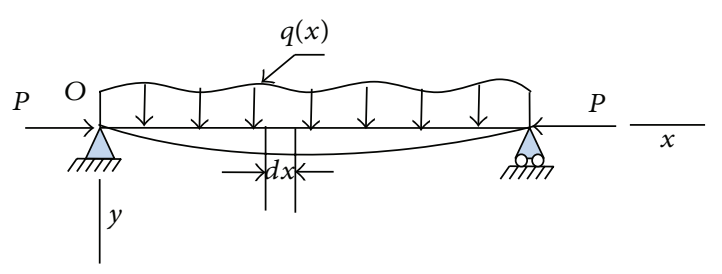

(a)

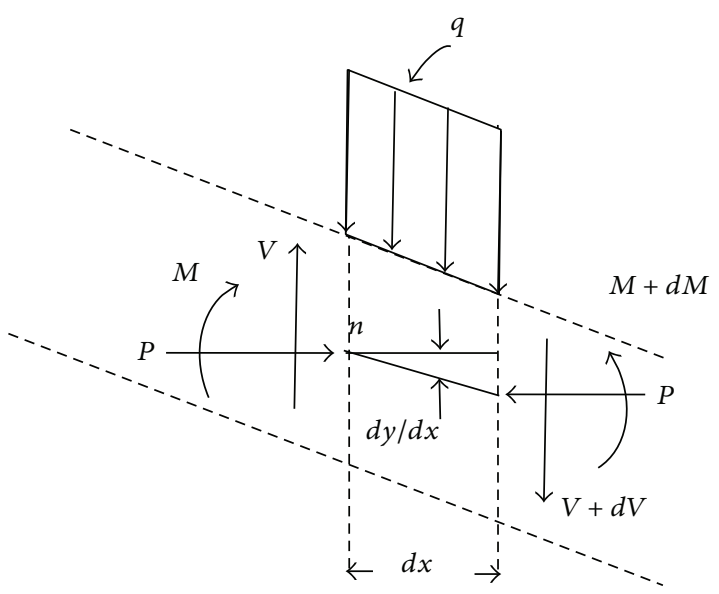

(b)

Figure 1: Cross-sectional analysis of thecolumn-beam element.

Since rotations are assumed to be small, if $d^{2} / d x^{2}=-M / E I$, then (14) becomes

$$
-V=E I \frac{d^{3} y}{d x^{3}}+P \frac{d y}{d x}
$$

Here, EI represents bending rigidity. If the derivative of both sides of (15) is taken in terms of $x$, then the fourth order linear differential equation for the elastic curve is found as such:

$$
E I \frac{d^{4} y}{d x^{4}}+P \frac{d^{2} y}{d x^{2}}=q(x)
$$

\subsection{Application of the ADM to the Problem}

Example 1. We consider the fourth order linear nonhomogeneous differential equation [43]:

$$
\frac{d^{4} y}{d x^{4}}-2 \frac{d^{2} y}{d x^{2}}+y=-8 e^{x}, \quad x \in[0,1]
$$

with the boundary conditions of

$$
y(0)=y^{\prime \prime}(0)=1, \quad y^{\prime}(1)=y^{\prime \prime}(1)=-e .
$$

If (18) is written out in operator form, we obtain

$$
L y=2 y^{\prime \prime}-y-8 e^{x} .
$$

Here,

$$
L=\frac{d^{4}}{d x^{4}}, \quad L^{-1}(\cdot)=\int_{0}^{x} \int_{0}^{x} \int_{0}^{x} \int_{0}^{x}(\cdot) d x d x d x d x
$$

are the derivative and integral operators. If the $L^{-1}$ inverse operator is applied to (19) and initial conditions are taken, we find

$$
y(x)=A x+\frac{1}{3 !} B x^{3}-8 L^{-1}\left(e^{x}\right)+2 L^{-1}\left(y^{\prime \prime}\right)-L^{-1}(y),
$$

where $A=y^{\prime}(0)$ and $B=y^{\prime \prime \prime}(0)$. If we use (3) in (21), then we find

$$
\begin{aligned}
\sum_{n=0}^{\infty} y_{n}(x)= & A x+\frac{1}{3 !} B x^{3}-8 L^{-1} e^{x} \\
& +2 L^{-1}\left(\sum_{n=0}^{\infty} y_{n}^{\prime \prime}(x)\right)-L^{-1}\left(\sum_{n=0}^{\infty} y_{n}(x)\right)
\end{aligned}
$$

whereas the reduction formula given below can be written using (22):

$$
\begin{array}{r}
y_{0}(x)=A x+\frac{1}{3 !} B x^{3}-8 L^{-1}\left(e^{x}\right) \\
y_{n+1}(x)=2 L^{-1}\left(y_{n}^{\prime \prime}\right)-L^{-1}\left(y_{n}\right) \\
n \geq 0 .
\end{array}
$$

The $A$ and $B$ constants in the reduction formula will be determined using boundary conditions (18) after finding the decomposition series. From the reduction relation, we can obtain the solution terms of the decomposition series as

$$
\begin{aligned}
y_{0}(x)= & 8-8 e^{x}+(8+A) x+4 x^{2}+\frac{1}{6}(8+B) x^{3}, \\
y_{1}(x)= & 8-8 e^{x}+8 x+4 x^{2}+\frac{4 x^{3}}{3}+\frac{x^{4}}{3} \\
& -\frac{1}{120}(-8+A-2 B) x^{5}-\frac{x^{6}}{90}-\frac{(8+B) x^{7}}{5040} \\
y_{2}(x)= & -8 e^{x}+8 x+4 x^{2}+\frac{4 x^{3}}{3}+\frac{x^{4}}{3}-\frac{x^{5}}{15}+\frac{x^{6}}{90} \\
& -\frac{(A-2(2+B)) x^{7}}{2520}-\frac{x^{8}}{1680} \\
+ & \frac{(A-4(6+B)) x^{9}}{362880}+\frac{x^{10}}{453600}+\frac{(8+B) x^{11}}{39916800},
\end{aligned}
$$

$$
y_{3}(x)=8-8 e^{x}+8 x+4 x^{2}+\frac{4 x^{3}}{3}+\frac{x^{4}}{3}+\frac{x^{5}}{15}
$$

$$
\begin{aligned}
& +\frac{x^{6}}{90}+\frac{x^{7}}{630}+\frac{x^{8}}{5040}-\frac{(-2+A-2 B) x^{9}}{90720} \\
& -\frac{x^{10}}{64800}+\frac{(-14+A-3 B) x^{11}}{9979200}
\end{aligned}
$$




$$
\begin{aligned}
+ & \frac{x^{12}}{11975040}-\frac{(-40+A-6 B) x^{13}}{6227020800} \\
& -\frac{x^{14}}{10897286400}-\frac{(8+B) x^{15}}{1307674368000}, \\
y_{4}(x)= & 8-8 e^{x}+8 x+4 x^{2}+\frac{4 x^{3}}{3}+\frac{x^{4}}{3}+\frac{x^{5}}{15} \\
& +\frac{x^{6}}{90}+\frac{x^{7}}{630}+\frac{x^{8}}{5040}+\frac{x^{9}}{45360} \\
& +\frac{x^{10}}{453600}-\frac{(-1+A-2 B) x^{11}}{4989600}-\frac{x^{12}}{3991680} \\
& +\frac{(-30+3 A-8 B) x^{13}}{1556755200}+\frac{17 x^{14}}{10897286400} \\
& -\frac{(-6 B+3 A-12 B) x^{15}}{653837184000}-\frac{x^{16}}{373621248000} \\
& +\frac{(A-8(7+B)) x^{17}}{355687428096000}+\frac{x^{18}}{800296713216000} \\
& +\frac{(8+B) x^{19}}{121645100408832000} .
\end{aligned}
$$

If these terms are placed in (4), we obtain the approximate solution obtained via the ADM using the five terms of (17) and problem (18) can be written as

$$
y(x)=\sum_{i=0}^{4} y_{i}(x)=y_{0}(x)+y_{1}(x)+y_{2}(x)+y_{3}(x)+y_{4}(x)
$$

$$
\begin{aligned}
y(x)= & 40-40 e^{x}+(40+A) x+20 x^{2}+\frac{1}{6}(40+B) x^{3} \\
& +\frac{4 x^{4}}{3}-\frac{1}{120}(A-2(16+B)) x^{5}+\frac{x^{6}}{45} \\
& -\frac{(-16+2 A-3 B) x^{7}}{5040}-\frac{x^{8}}{5040} \\
& -\frac{(8+3 A-4 B) x^{9}}{362880}-\frac{x^{10}}{90720}-\frac{(40+4 A-5 B) x^{11}}{39916800} \\
& -\frac{x^{12}}{5987520}+\frac{(-80+11 A-26 B) x^{13}}{6227020800}+\frac{x^{14}}{681080400} \\
& -\frac{(-128+6 A-23 B) x^{15}}{1307674368000}-\frac{x^{16}}{373621248000} \\
& +\frac{(A-8(7+B)) x^{17}}{355687428096000}+\frac{x^{18}}{800296713216000} \\
& +\frac{(8+B) x^{19}}{121645100408832000} .
\end{aligned}
$$

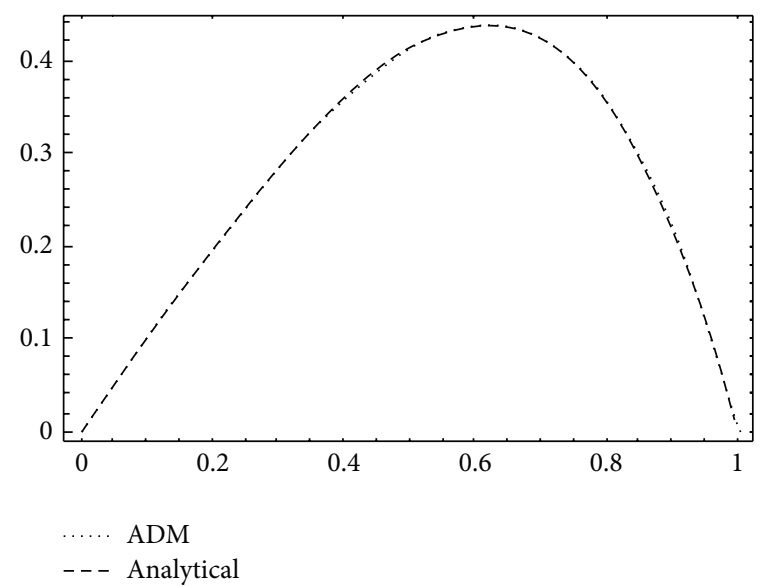

FIGURE 2: Graph showing the ADM and analytical solution obtained using the five terms of the decomposition series.

TABLE 1: Numerical results obtained using the five terms of the decomposition series.

\begin{tabular}{lccc}
\hline$x$ & $\begin{array}{c}\text { Analytical } \\
\text { solution } y(x)\end{array}$ & $\begin{array}{c}\text { Approximate } \\
\text { solution } \emptyset_{5}\end{array}$ & $\begin{array}{c}\text { Error } \\
\left|y(x)-\emptyset_{5}\right|\end{array}$ \\
\hline 0 & 0. & 0. & 0. \\
0.1 & 0.099465 & 0.099465 & $2.92821 \times 10^{-15}$ \\
0.2 & 0.195424 & 0.195424 & $-2.16493 \times 10^{-15}$ \\
0.3 & 0.283470 & 0.283470 & $6.10623 \times 10^{-16}$ \\
0.4 & 0.358038 & 0.358038 & $-1.30451 \times 10^{-13}$ \\
0.5 & 0.412180 & 0.412180 & $-2.37055 \times 10^{-12}$ \\
0.6 & 0.437309 & 0.437309 & $-2.58711 \times 10^{-11}$ \\
0.7 & 0.422888 & 0.422888 & $-1.94957 \times 10^{-10}$ \\
0.8 & 0.356087 & 0.356087 & $-1.12373 \times 10^{-9}$ \\
0.9 & 0.221364 & 0.221364 & $-5.27758 \times 10^{-9}$ \\
1.0 & $\mathbf{0 .}$ & $\mathbf{2 . 1 0 8 8 4} \times \mathbf{1 0}^{-8}$ & $-\mathbf{2 . 1 0 8 8 4} \times \mathbf{1 0}^{-8}$ \\
\hline
\end{tabular}

If we use boundary conditions (18) in solutions series (26), then we have $A=1$ and $B=-3$. The analytical solution of problem (17) and (18) is [43]

$$
y(x)=x(1-x) e^{x} .
$$

The numerical results and graphs obtained for five terms using the solution series in (26) have been given below.

\section{Results and Discussion}

In this study, the approximate solution of the fourth order boundary value problem arising in beam-column theory has been determined using the ADM. This method can be applied on differential equations without the need for discretization, indexing, or linearization.

Nonhomogeneous problem has been handled regarding the topic and the obtained results have been given in Table 1 and Figure 2. As can be seen from the table and figure, the method used has given results that converge rapidly to the analytical solution with the removal of a few terms from the 
TABLE 2: Comparison of the absolute error obtained using the spline method (SM) and the ADM.

\begin{tabular}{lcccc}
\hline$x$ & SM & SM & ADM & CPU time \\
\hline 0 & $h=1 / 5$ & $h=1 / 10$ & $\emptyset_{5}$ & \\
0.2 & 0 & 0 & 0 & 0.542 \\
0.4 & $1.960 E-5$ & $1.228 E-6$ & $-2.164 E-15$ & 0.846 \\
0.6 & $3.211 E-5$ & $2.012 E-6$ & $-1.304 E-13$ & 0.870 \\
0.8 & $2.683 E-5$ & $1.681 E-6$ & $-1.123 E-9$ & 0.891 \\
1 & 0 & 0 & $-2.108 E-8$ & 0.902 \\
\hline
\end{tabular}

solution series. This shows that the method is suitable and reliable for such problems. In addition, the handled example has been compared with the results obtained by Chen and Atsuta [41, 42] using nonpolynomial spline method. As seen in Table 2 values close to those obtained in this study were found only in case when the " $h$ " step was small. New terms can be added to the solution series of the ADM to obtain results that are much better than those of the spline method.

In Figure 2, five terms of the decomposition method have been taken from the analytical solution and decomposition series of example have been drawn in two dimensional graphs. As seen in these graphs, the analytical and approximate solutions cannot be distinguished.

In conclusion, it has been determined that the ADM can be applied to the linear homogeneous and nonhomogeneous boundary value problems that arise in civil engineering in the beam-column theory. Solutions that converge rapidly to the analytical solution can be found without changing the nature of the physical phenomenon. In addition, the calculations for this method can be carried out using software such as Mathematica, Maple, and Matlab.

\section{Conflict of Interests}

The author declares that there is no conflict of interests.

\section{References}

[1] G. Adomian, Solving Frontier Problems of Physics: The Decomposition Method, Kluwer Academic Publishers, Boston, Mass, USA, 1994.

[2] G. Adomian, "A review of the decomposition method and some recent results for nonlinear equations," Mathematical and Computer Modelling, vol. 13, no. 7, pp. 17-43, 1990.

[3] G. Adomian and R. Rach, "Equality of partial solutions in the decomposition method for linear or nonlinear partial differential equations," Computers \& Mathematics with Applications, vol. 19, no. 12, pp. 9-12, 1990.

[4] M. Inc, "On numerical solutions of partial differential equations by the decomposition method," Kragujevac Journal of Mathematics, vol. 26, pp. 153-164, 2004.

[5] M. Inc, "Decomposition method for solving parabolic equations in finite domains," Journal of Zhejiang University SCIENCE A, vol. 6, no. 10, pp. 1058-1064, 2005.
[6] M. Inc, Y. Cherruault, and K. Abbaoui, "A computational approach to the wave equations: an application of the decomposition method," Kybernetes, vol. 33, no. 1, pp. 80-97, 2004.

[7] Z. M. Odibat, "A new modification of the homotopy perturbation method for linear and nonlinear operators," Applied Mathematics and Computation, vol. 189, no. 1, pp. 746-753, 2007.

[8] S. R. S. Alizadeh, G. G. Domairry, and S. Karimpour, "An approximation of the analytical solution of the linear and nonlinear integro-differential equations by homotopy perturbation method," Acta Applicandae Mathematicae, vol. 104, no. 3, pp. 355-366, 2008.

[9] Y.-G. Wang, H.-F. Song, and D. Li, "Solving two-point boundary value problems using combined homotopy perturbation method and Green's function method," Applied Mathematics and Computation, vol. 212, no. 2, pp. 366-376, 2009.

[10] J. Biazar and H. Ghazvini, "Convergence of the homotopy perturbation method for partial differential equations," Nonlinear Analysis: Real World Applications, vol. 10, no. 5, pp. 2633-2640, 2009.

[11] C.-S. Liu, "The essence of the homotopy analysis method," Applied Mathematics and Computation, vol. 216, no. 4, pp. 12991303, 2010.

[12] S. Momani and S. Abuasad, "Application of He's variational iteration method to Helmholtz equation," Chaos, Solitons \& Fractals, vol. 27, no. 5, pp. 1119-1123, 2006.

[13] E. M. Abulwafa, M. A. Abdou, and A. A. Mahmoud, "Nonlinear fluid flows in pipe-like domain problem using variationaliteration method," Chaos, Solitons \& Fractals, vol. 32, no. 4, pp. 1384-1397, 2007

[14] N. H. Sweilam and M. M. Khader, "Variational iteration method for one dimensional nonlinear thermoelasticity," Chaos, Solitons \& Fractals, vol. 32, no. 1, pp. 145-149, 2007.

[15] L. Xu, "Variational iteration method for solving integral equations," Computers \& Mathematics with Applications, vol. 54, no. 7-8, pp. 1071-1078, 2007.

[16] J.-H. He, A.-M. Wazwaz, and L. Xu, "The variational iteration method: reliable, efficient, and promising," Computers \& Mathematics with Applications, vol. 54, no. 7-8, pp. 879-880, 2007.

[17] L. Xu, J.-H. He, and A.-M. Wazwaz, "Preface variational iteration method-reality, potential, and challenges," Journal of Computational and Applied Mathematics, vol. 207, no. 1, pp. 1-2, 2007.

[18] S. B. Coşkun and M. T. Atay, "Analysis of convective straight and radial fins with temperature-dependent thermal conductivity using variational iteration method with comparison with respect to finite element analysis," Mathematical Problems in Engineering, vol. 2007, Article ID 42072, 15 pages, 2007.

[19] M. T. Atay and S. B. Coşkun, "Effects of nonlinearity on the variational iteration solutions of nonlinear two-point boundary value problems with comparison with respect to finite element analysis," Mathematical Problems in Engineering, vol. 2008, Article ID 857296, 10 pages, 2008.

[20] M. Inc and Y. Uğurlu, "Numerical simulation of the regularized long wave equation by He's homotopy perturbation method," Physics Letters A: General, Atomic and Solid State Physics, vol. 369, no. 3, pp. 173-179, 2007.

[21] A. S. Bataineh, M. S. M. Noorani, and I. Hashim, "Homotopy analysis method for singular IVPs of Emden-Fowler type," Communications in Nonlinear Science and Numerical Simulation, vol. 14, no. 4, pp. 1121-1131, 2009. 
[22] S. Abbasbandy, E. Babolian, and M. Ashtiani, "Numerical solution of the generalized Zakharov equation by homotopy analysis method," Communications in Nonlinear Science and Numerical Simulation, vol. 14, no. 12, pp. 4114-4121, 2009.

[23] M. M. Rashidi and S. Dinarvand, "Purely analytic approximate solutions for steady three-dimensional problem of condensation film on inclined rotating disk by homotopy analysis method," Nonlinear Analysis: Real World Applications, vol. 10, no. 4, pp. 2346-2356, 2009.

[24] L. Song and H. Zhang, "Solving the fractional BBM-Burgers equation using the homotopy analysis method," Chaos, Solitons \& Fractals, vol. 40, no. 4, pp. 1616-1622, 2009.

[25] S. Liao, "On the relationship between the homotopy analysis method and Euler transform," Communications in Nonlinear Science and Numerical Simulation, vol. 15, no. 6, pp. 1421-1431, 2010.

[26] G. Adomian, Nonlinear Stochastic Operator Equations, Academic Press, San Diego, Calif, USA, 1986.

[27] M. Inc and M. Işık, "Adomian decomposition method for threedimensional parabolic equation with non-classic boundary conditions," Journal of Analysis, vol. 11, pp. 43-51, 2003.

[28] F. Abdelwahid, "A mathematical model of Adomian polynomials," Applied Mathematics and Computation, vol. 141, no. 2-3, pp. 447-453, 2003.

[29] E. Babolian and S. Javadi, "New method for calculating Adomian polynomials," Applied Mathematics and Computation, vol. 153, no. 1, pp. 253-259, 2004.

[30] Y. Cherruault, M. Inc, and K. Abbaoui, "On the solution of the non-linear Korteweg-de Vries equation by the decomposition method," Kybernetes, vol. 31, no. 5, pp. 766-772, 2002.

[31] A. M. A. El-Sayed and M. Gaber, “The Adomian decomposition method for solving partial differential equations of fractal order in finite domains," Physics Letters A, vol. 359, no. 3, pp. 175-182, 2006.

[32] E. Momoniat, T. A. Selway, and K. Jina, "Analysis of Adomian decomposition applied to a third-order ordinary differential equation from thin film flow," Nonlinear Analysis: Theory, Methods \& Applications, vol. 66, no. 10, pp. 2315-2324, 2007.

[33] L. L. Thompson and P. M. Pinsky, "A Galerkin least-squares finite element method for the two-dimensional Helmholtz equation," International Journal for Numerical Methods in Engineering, vol. 38, no. 3, pp. 371-397, 1995.

[34] J. Dolbow and T. Belytschko, "Numerical integration of the Galerkin weak form in meshfree methods," Computational Mechanics, vol. 23, no. 3, pp. 219-230, 1999.

[35] S. N. Atluri and T. Zhu, "A new meshless local Petrov-Galerkin (MLPG) approach in computational mechanics," Computational Mechanics, vol. 22, no. 2, pp. 117-127, 1998.

[36] A. M. Wazwaz, Partial Differential Equations: Methods and Applications, Balkema Publishers, Rotterdam, The Netherlands, 2002.

[37] Y. Cherruault, “Convergence of Adomian's method," Kybernetes, vol. 18, no. 2, pp. 31-38, 1989.

[38] K. Abbaoui and Y. Cherruault, "New ideas for proving convergence of decomposition methods," Computers \& Mathematics with Applications, vol. 29, no. 7, pp. 103-108, 1995.

[39] S. P. Timoshenko and J.M. Gere, Theory of Elastic Stability, McGraw-Hill, New York, NY, USA, 2nd edition, 1961.

[40] S. P. Timoshenko and J.M. Gere, Theory of Elastic Stability, McGraw-Hill, New York, NY, USA, 1985.
[41] W. F. Chen and T. Atsuta, Theory of Beam-Columns, vol. 1 of Inplane Behavior and Design, McGraw-Hill, New York, NY, USA, 1976.

[42] W. F. Chen and T. Atsuta, Theory ofBeam-Columns, vol. 2 of Space Behavior and Design, McGraw-Hill, New York, NY, USA, 1977.

[43] O. A. Taiwo and O. M. Ogunlaran, "A non-polynomial spline method for solving linear fourth-order boundary-value problems," International Journal of Physical Sciences, vol. 6, no. 13, pp. 3246-3254, 2011. 


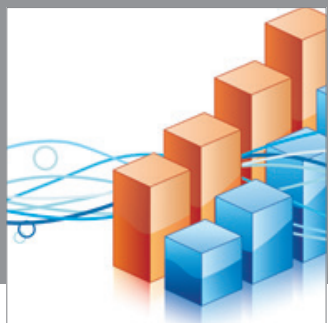

Advances in

Operations Research

mansans

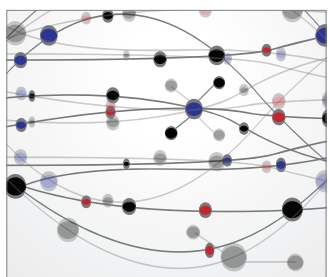

The Scientific World Journal
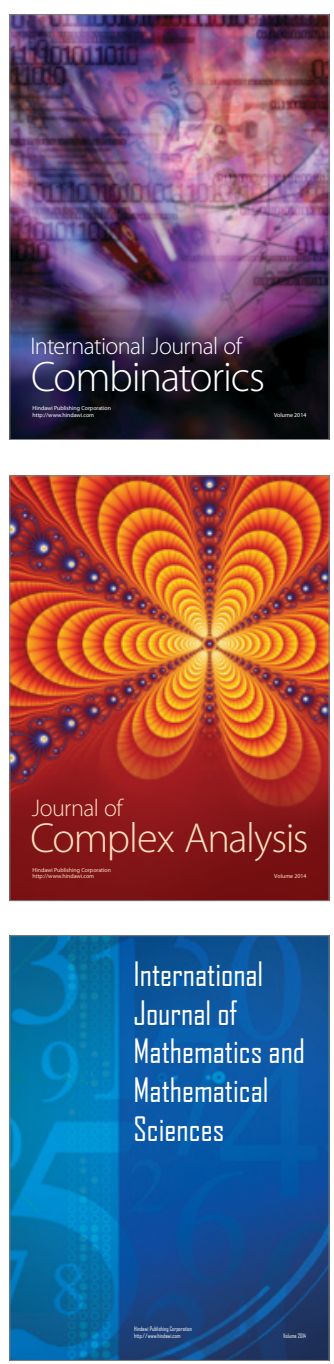
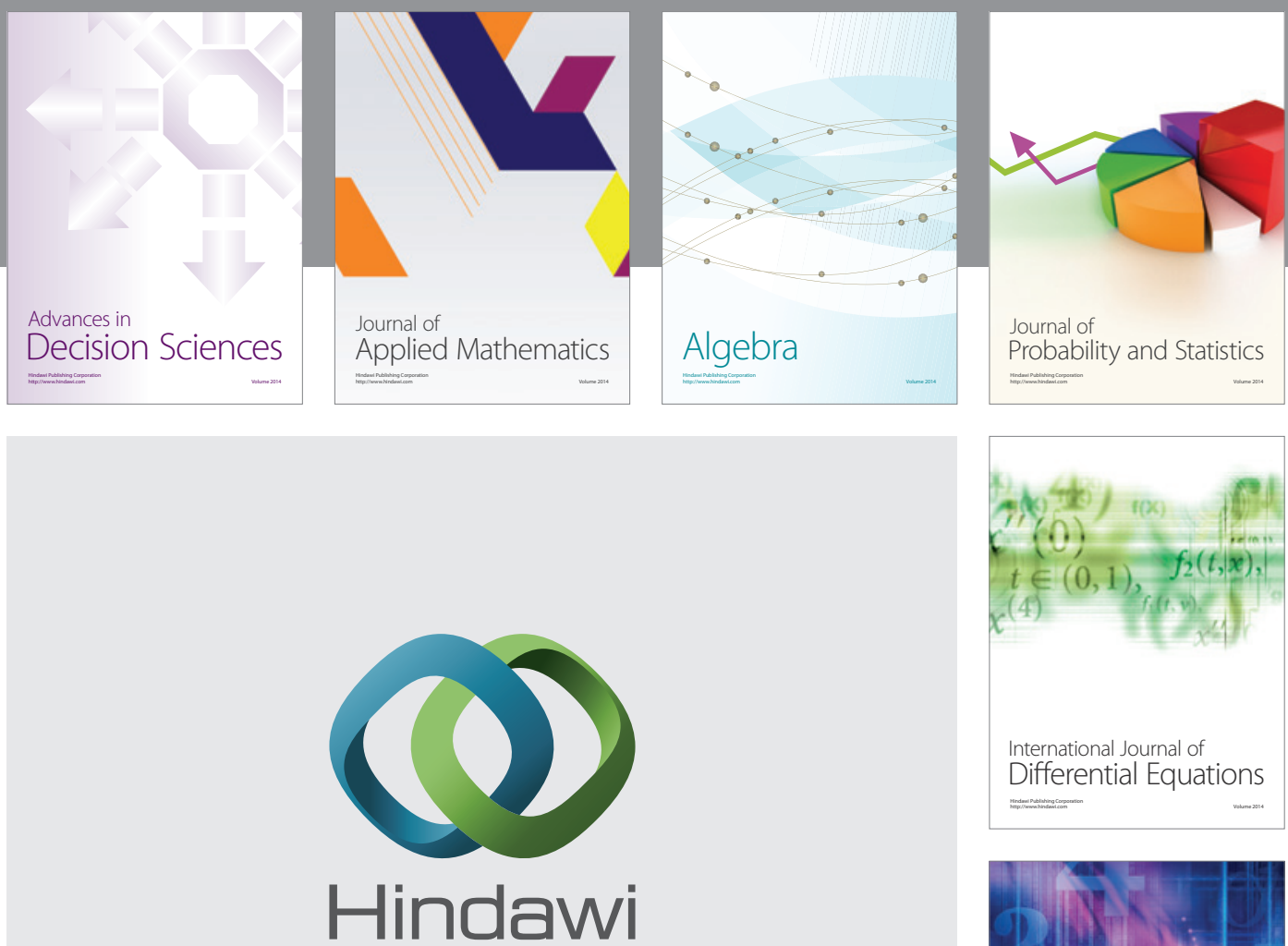

Submit your manuscripts at http://www.hindawi.com
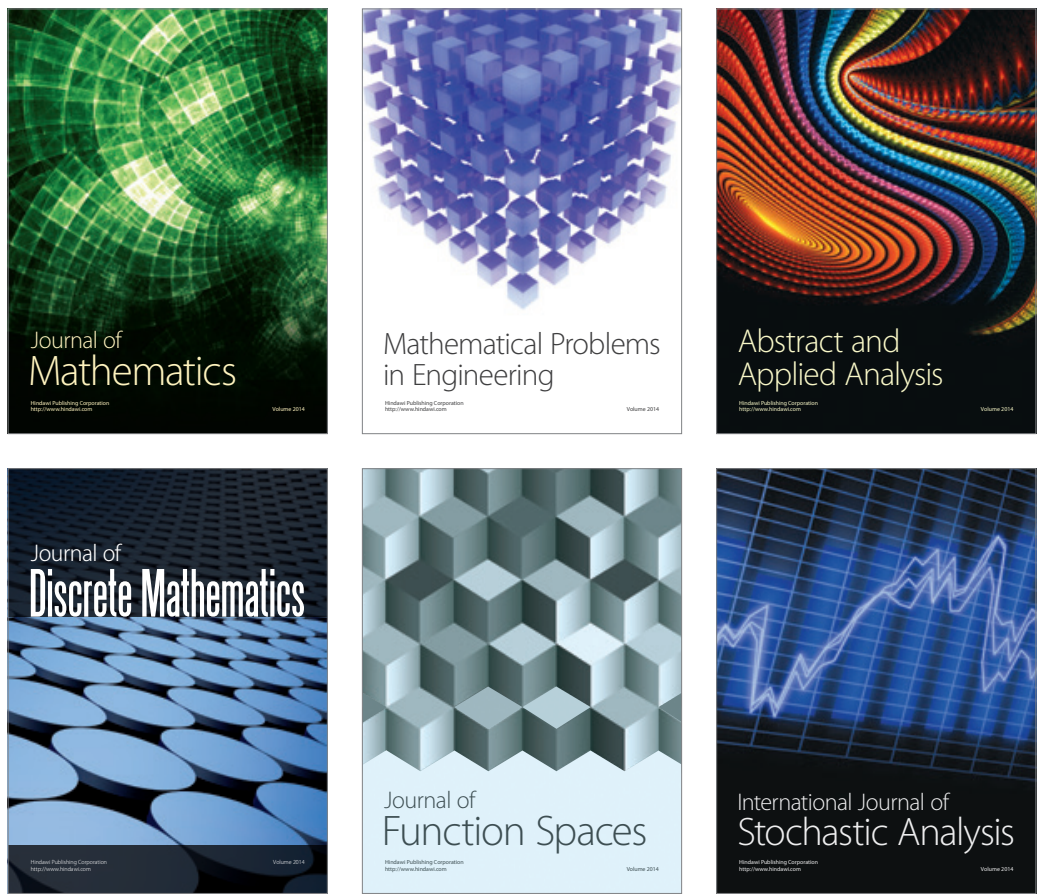

Journal of

Function Spaces

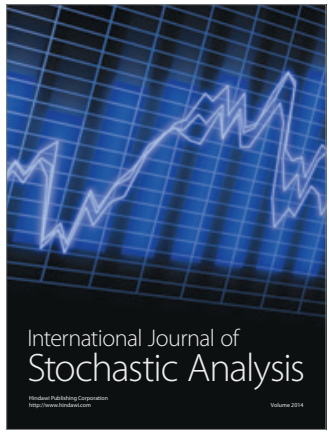

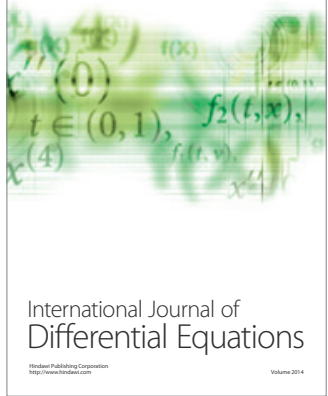
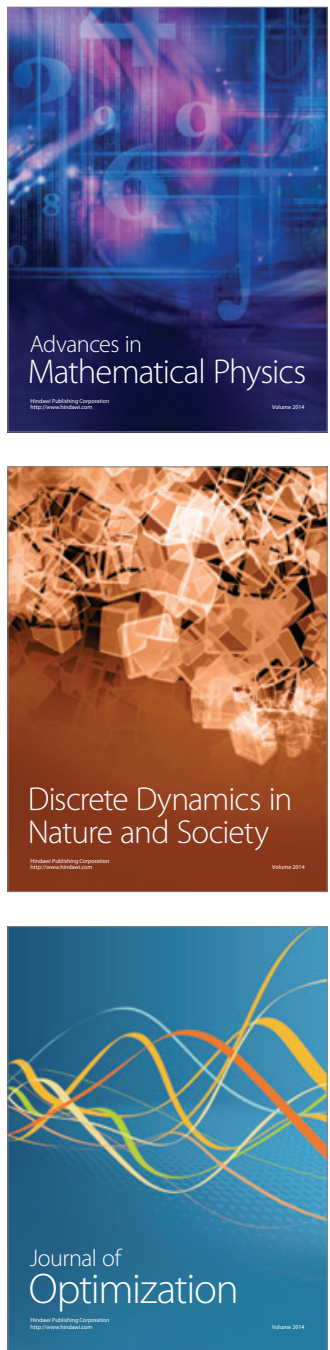